\title{
Caloric compensation in preschool children: relationships with body mass and differences by food category
}

\author{
S Carnell ${ }^{1}$, L Benson ${ }^{1}$, EL Gibson ${ }^{2}$, LA Mais ${ }^{3}$, and S Warkentin ${ }^{3}$ \\ ${ }^{1}$ Division of Child and Adolescent Psychiatry, Department of Psychiatry and Behavioral Sciences, \\ Johns Hopkins University School of Medicine, Baltimore, MD \\ ${ }^{2}$ Department of Psychology, University of Roehampton, London, UK \\ ${ }^{3}$ Discipline of Nutrology, Department of Pediatrics, Federal University of São Paulo (UNIFESP), \\ São Paulo, SP, Brazil/Division of Child \& Adolescent Psychiatry, Department of Psychiatry \& \\ Behavioral Sciences, Johns Hopkins University School of Medicine, Baltimore, MD, USA
}

\section{Abstract}

Maintaining a healthy weight may involve compensating for previously consumed calories at subsequent meals. To test whether heavier children demonstrated poorer caloric compensation across a range of conditions, and to explore whether compensation failure was the result of inadequate adjustment of overall intake or specific over-consumption of highly palatable, high energy-density 'junk' foods, we administered two compensation tests to a sample of 4-5 y olds. For Test A, preloads varied only in carbohydrate content and were organoleptically indistinguishable ( $200 \mathrm{ml}$ orange-flavored beverage [0 kcal vs. $200 \mathrm{kcal}])$. For Test B, the preloads varied substantially in both macronutrient composition and learned gustatory cues to caloric content $(200 \mathrm{ml}$ water [0 kcal] vs. $200 \mathrm{ml}$ strawberry milkshake [200 kcal]). Each preload was followed 30 minutes later by a multi-item ad libitum meal containing junk foods (chocolate cookies, cheese-flavored crackers) and core foods (fruits and vegetables, bread rolls, protein foods). Testing took place at the children's own school under normal lunch-time conditions. Children were weighed and measured. Caloric compensation occurred in both tests, in terms of total, junk and core food intake (RMANOVA, all $\mathrm{p}<.01$ ). Higher BMI z scores were associated with greater average caloric compensation $(r=-.26 ; p<.05)$, such that overweight/obese children showed least compensation (41\%), children over the $50^{\text {th }}$ centile the next least $(59 \%)$, and children under the $50^{\text {th }}$ centile $(80 \%)$ the most. For Test A only, obese/overweight children compensated less well than normal-weight children in terms of junk food intake (RMANOVA preload-byweight group interaction $\mathrm{p}<.05)$, with no effect for core foods. Our results suggest that caloric compensation is consistently poorer in heavier children, and that overweight/obese children's preferences for junk foods may overwhelm intake regulation mechanisms within meals containing those foods.

Correspondence to: Susan Carnell, PhD, Johns Hopkins University School of Medicine, Division of Child \& Adolescent Psychiatry, Department of Psychiatry and Behavioral Sciences, 600 N. Wolfe St/Phipps 300, Baltimore, MD 21287, Phone: 410-955-7192; Fax: 410-614-3676; susan.carnell@jhmi.edu.

Publisher's Disclaimer: This is a PDF file of an unedited manuscript that has been accepted for publication. As a service to our customers we are providing this early version of the manuscript. The manuscript will undergo copyediting, typesetting, and review of the resulting proof before it is published in its final citable form. Please note that during the production process errors may be discovered which could affect the content, and all legal disclaimers that apply to the journal pertain. 


\section{Keywords}

food choice; high calorie; adiposity; fatness; body weight

\section{Introduction}

A continual process of caloric compensation, i.e. the regulation of energy intake by adjusting one's intake based on previous consumption, may be required for maintaining energy balance and remaining at a healthy body weight. This process could be entirely subconscious and therefore amenable to measurement in young children, who are less likely than adults to exert conscious control over their food intake. Several early and influential papers have made convincing arguments that the ability to compensate is naturally present in the majority of infants and young children when given a nutritionally balanced set of foods (1-3), and data from laboratory tests (4), controlled feeding studies (5) and 24-h dietary recalls (6) have provided some degree of support.

If compensation ability differs between individuals and influences body weight, we would expect heavier children to exhibit poorer compensation ability. This has important implications, since failure to compensate beginning in childhood could have a large cumulative effect on weight over the lifetime. Caloric compensation is most commonly tested in the laboratory using a preloading paradigm, in which ad libitum intake is assessed following a higher-energy or lower-energy preload, within a repeated-measures design, and the degree of compensation for the difference in preload intake is calculated, typically using the following equation: $\mathrm{COMPX}=(($ lunch calories after low energy preload - lunch calories after high energy preload) / (high energy preload calories - low energy preload calories) $) \times$ 100 (Johnson \& Birch (7)). Using this method in a sample of preschool children, Johnson \& Birch (7) assessed compensation for high-energy (150 kcal) vs. low-energy (3 kcal) juice preloads, similar in flavor and appearance, at a ad libitum multi-item lunch (turkey hot dogs, cheese slices, applesauce, carrots, fig newtons and $2 \%$ milk) consumed 20 minutes afterwards. Mean COMPX was $46.2 \pm 5.7 \%$, with a range of $-80 \%$ to $230 \%$, and there was a significant negative association ( $\mathrm{r}=-.37$ ) between compensation and adiposity in girls only, such that poorer compensation was associated with greater sub-scapular skinfolds and relative weight-for-height. Associations with adiposity have been observed in older children (8) and adults $(9,10)$ too.

However, in parallel with the positive findings reported above, it should be noted that many studies have failed to find associations with child adiposity. Using a similar paradigm to that described in (7), in which 3-7 y old sibling pairs were given a high (150 kcal) or low (3 $\mathrm{kcal}$ ) calorie fruit drink preload, and then provided with a multi-item meal (macaroni and cheese, canned string beans, string cheese, graham crackers, green grapes, baby carrots and whole milk; $800 \mathrm{kcal}) 25$ minutes later, Faith et al (11) tested caloric compensation and observed mean COMPX of 104\% +/- 107\% SD, but no relationship with child weight. Another study administered low-energy (187 kcal) and high-energy (389 kcal) muffin and orange juice preloads, as well as a no-energy preload (water), followed 90 min later by an ad libitum lunch including items such as ham, cheese, carrots, cucumbers, crackers, juice and 
water, in a sample of 6-9 y olds tested in a laboratory setting and found that younger children showed greater compensation, but compensation ability was unrelated to child weight (12). In a study of 3-6 year olds, intake of a standard lunch containing beef lasagna, cheese, carrot, apple puree and white bread was measured on separate days at the school canteen at lunch time, once 30 minutes after a chocolate bun preload (137 kcal) and once with no preceding preload, and children compensated $52.5+/-4.4 \%$ SD but compensation was uncorrelated with child BMI z score (13).

Associations between weight and compensation may depend somewhat on the choice of preloads. This is illustrated by several studies administering varying forms of preload test within the same sample $(8,14)$, and matching characteristics such as caloric content, flavor and appearance between preloads $(8,14)$. For example, in a study of $9-14$ y old boys, although an effect was seen with whey protein drink preloads, there was no association with weight when glucose preload drinks were used (8). In another study, Wilson (15) found that preschool children ate $25 \%$ more total energy when served chocolate milk with their meals compared to plain milk. Further, in a study of obese and lean adults, while both groups showed hunger and energy reduction at a buffet meal 180 minutes later following a high protein preload meal, the obese group failed to demonstrate the energy reduction following a matched high fat preload meal that the lean group showed, and relative to the lean group, showed increased energy intake following high fat and high carbohydrate preload meals, but not after high or adequate protein preload meals (14). These mixed findings may partly result from differences in the relative satiating ability of different dietary components (16, 17) but also potentially due to differences in palatability (18) or previously established eating habits.

Certainly, energy intake regulation during free-living eating behavior may be influenced by previously learned expectations of energy delivery (19), which are often artificially equated within preload studies using disguised manipulation of energy intake (e.g. $(7,9,11,20)$ ). For example, if we consume a thick milkshake, the perceptual and gustatory experience may consciously or subconsciously activate associations with increased post-ingestive satiety sensations which could lead us to substantially decrease our intake at a subsequent meal, even before macronutrient-dependent post-ingestive satiety effects peak 1-2 hours after preload ingestion (21). In contrast, if we consume a calorie-dense version of a beverage that we customarily consume in a less calorie-dense form (as in disguised preload studies), we may consciously or subconsciously underestimate post-ingestive satiety, leading to a failure to compensate (22). Energy intake in an experimental setting could also depend on habits independent of macronutrient-related satiation or learned expectations of satiety. So, for example, habitual consumption of a familiar beverage in close proximity to a meal may lead to inadequate compensation for its caloric load in situations where the caloric load is unusually high.

Although a few studies have examined the effects on compensation of varying preload types, fewer studies have asked the opposite question, i.e. might associations between weight and compensation depend on the composition of the ad libitum meal that is made available? However, one study of young adult men (BMI $21.3 \pm 0.5$ ) found that in response to both a low-energy and a high-energy preload of instant soup, subjects ate significantly more, and 
compensated less, when offered a palatable (pasta with sauce) rather than a bland (plain pasta) lunch (23), highlighting a potential role for palatability and energy density. As far as we are aware, no studies have addressed the issue of how differing energy preloads affect the composition of the meal that is selected and consumed by participants when they are given access to a multi-item ad libitum meal, and whether this is associated with weight. For example, is the poorer compensation that has been reported in overweight individuals predominantly attributable to hedonic overeating of highly palatable high-calorie foods, or to indiscriminate overeating of all food groups? This is of interest, because if it is the highenergy/junk foods in particular that are being overeaten, then limiting available foods to relatively healthy core food items may improve compensation behavior.

Many of the discrepancies in previous preload studies are likely to relate to methodological variance between experiments (e.g. differences in preloads, length of preload-meal gap, constituents of ad lib meals, age of sample), and some of the negative findings in particular may be the result of extraneous influences affecting the single preload test conducted. In this study we therefore wanted to address two main questions: 1) Is compensation consistently impaired in heavier children across two different types of preload manipulation-one involving organoleptically indistinguishable preloads varying only in carbohydrate content (low vs. high energy orange, e.g. $(7,11)$ and one involving familiar beverages varying substantially in both macronutrient composition and sensory properties and thereby learned gustatory cues to caloric content (water vs. milkshake, e.g. $(8,13)$ ? 2) If compensation is impaired, what are the microstructural characteristics of the impairment, i.e. do heavier children fail to compensate specifically in terms of their intake of obesogenic junk foods, of core foods, or across all food groups? To do this we recruited a sample of 4-5 y olds and administered two different preload challenges. We then tested compensation for caloric content at a subsequent multi-item meal.

Since failure to compensate early in childhood could have a large cumulative effect on weight over the lifetime, we chose to use a sample of preschool children, as have other investigators $(7,11-13,20)$. Similar to much of the previous work in preschoolers $(7,11,13$, 20), we presented each meal 30 minutes after the preload, thereby maximizing the likelihood of compensation based on sensory properties and learned expectations of energy delivery. Since other studies have demonstrated compensation effects with preload energy differences of $200 \mathrm{kcal}$ or less $(7,11,20)$, we opted for a preload energy difference of $200 \mathrm{kcal}$, with one preload being extremely low in energy $(7,8,11)$. To increase ecological validity, we chose a lunch meal containing a range of foods commonly consumed at lunch-time by this age group, and administered the lunch at the children's own school over a normal lunch-time, with children eating at tables together as for their normal lunch session. To facilitate investigation of meal composition in order to explore the microstructure of compensation (i.e. for which food categories did heavier children fail to adjust their intake), the meal contained a selection of higher energy-density 'junk' foods and lower energy-density 'core' foods. As we were interested in relationships between COMPX and body mass throughout the continuum, our main analysis of interest was the correlation between COMPX and BMI $\mathrm{z}$ score. However, for descriptive purposes, we also reported COMPX scores across different weight groups. We additionally explored differences in the microstructure of compensation between overweight/obese with normal-weight children. 


\section{Methods}

\section{Participants}

Greater London schools with nursery (3-4 years old) and reception (5 years old) classes that were located within an hour's travel time of the research centre were identified using local government lists, and head teachers were contacted by letter. All schools agreeing to participate were located in the lowest quartile of deprivation for their borough, as indexed by free school meal eligibility. Questionnaires were distributed directly to parents as they delivered or collected their children from school for completion at home, and reminder questionnaires were sent after four weeks to non-responders. The study protocol and consent forms were approved by the University College London Ethics Committee, where the study was conducted.

\section{Study protocol}

On Day 1 (control day), children submitted parental consent forms, were weighed and measured, then participated in a multi-item lunch at their usual scheduled lunch time. On Days 2-3 children underwent preload Test A (disguised caloric cues). For this test, half of the participating children were randomly allocated to receive the high energy preload on Day 2, and half the low energy preload on Day 2; they each received the alternative preload on Day 3. On Days 4-5 children completed preload Test B (undisguised caloric cues), for which a similar protocol was followed. Thirty minutes after the preload on each day the children were given a multi-item lunch meal. All procedures took place in classrooms with which the children were familiar.

\section{Measures}

Child weight and height-Children's heights were measured using a Leicester height measure and weights were measured in kilograms to one decimal place using a TANITA digital weighing scale on Day 1. All measurements were conducted by trained research staff.

Preload tests-Children were given each preload in a clear plastic cup with lid and straw and told they had 5 minutes to drink it. Research staff circulated towards the end of the consumption period to encourage children to finish any remaining liquid and to note any children who disliked the preload. At the end of this period they collected the cups and recorded the volume of any remaining liquid. The procedure was similar for Tests A and B. However, as the preloads were visibly different for Test B, children were told that they had been divided into teams, and that next week the teams would swap over, so everyone would get the chance to try each of the drinks.

Test A preloads (low vs. high energy orange: For Test A, the energy content of each preload was disguised. The low energy preload (total energy $=0 \mathrm{kcal}$ ) consisted of $200 \mathrm{ml}$ ( $0.4 \mathrm{~g}$ carbohydrate, $0.4 \mathrm{~g}$ sugars, under $0.2 \mathrm{~g}$ protein, and under $0.2 \mathrm{~g}$ fat (of which $0.2 \mathrm{~g}$ saturated)) of diluted Sainsbury's Orange and Mango Squash (J Sainsbury plc) made to the manufacturer's instructions of 1 part squash to 4 parts water ( $40 \mathrm{ml}$ squash, $160 \mathrm{ml}$ water). The high energy preload (total energy $=200 \mathrm{kcal}$ ) was similar but the soluble glucose polymer maltodextrin was added to increase calorie content without affecting taste (Polycose 
powder, Abbott Labs). To allow for an increase in volume with the addition of the powder, $22.5 \mathrm{~g}$ of Polycose was added for every $200 \mathrm{ml}$ of squash, creating a $20 \%$ solution. A $200 \mathrm{ml}$ measure of the resulting drink had a similar macronutrient composition to the low calorie squash, except that the carbohydrate content was increased to $22.9 \mathrm{~g}$.

Test B preloads (water vs. milkshake: For Test B, the energy content of the preloads was undisguised and differed in taste, appearance and macronutrient content. The low energy preload was Sainsbury's Caledonian Spring water (J Sainsbury plc) (total energy $=0 \mathrm{kcal}$ ). The high energy preload was Marks \& Spencer's Strawberry Milk (St Michael Foods plc), a highly palatable milk-based drink. Based on manufacturers' information, a $200 \mathrm{ml}$ measure contained $22.0 \mathrm{~g}$ carbohydrate, of which $21.8 \mathrm{~g}$ were sugars, $8.4 \mathrm{~g}$ protein, and $7.0 \mathrm{~g}$ fat (of which $4.4 \mathrm{~g}$ was saturated) (total energy $=200 \mathrm{kcal}$ ).

Multi-item lunch-At a school-specified lunch-time (c. 12pm-1pm), which was consistent across each of the five days of the study, children were seated in randomly selected groups of 5-6 around tables in their classrooms, with boys and girls seated alternately. Each child was then presented with a partitioned Tupperware tray ('Party Susan') containing 5 chicken slices $(4.10 \mathrm{kcal} / \mathrm{g}), 4$ cheese slices $(1.17 \mathrm{kcal} / \mathrm{g}), 3$ halves of white bread roll $(2.68 \mathrm{kcal} / \mathrm{g})$, mini cheese crackers $(5.29 \mathrm{kcal} / \mathrm{g})$, mini chocolate biscuits $(5.16 \mathrm{kcal} / \mathrm{g})$, and white grapes $(0.18 \mathrm{kcal} / \mathrm{g})$. A portion of vegetables was also provided: 8 cherry tomatoes $(0.18 \mathrm{kcal} / \mathrm{g})$ for the first group of children, and carrot sticks $(0.35 \mathrm{kcal} / \mathrm{g})$ for the next four groups, because the tomatoes were unexpectedly unpopular and we did not want to create a floor effect. Children were told that they could eat as much of their 'special lunch' as they wanted but not to share it with other children. They were told to start with their sandwiches at the front of the tray, and that if they dropped something they should inform one of the research team. If a child finished the bread rolls, additional halves were offered. Children were given a plastic cup of water to drink with their meal, which was refilled on their request. Research staff supervised the lunch and collected any discarded food in order to replace it on the correct tray to be weighed later.

\section{Data analysis}

Body mass index (BMI, $\mathrm{kg} / \mathrm{m}^{2}$ ) was calculated and converted into age- and sex-adjusted standard deviation scores (BMI z scores) according to 1990 British reference data (24). Overweight and obese status was derived on the basis of International Obesity Taskforce (IOTF, now World Obesity Clinical Care) criteria (25) and, for descriptive purposes, the normal-weight group was further subdivided into 'lower weight' ( 50 th centile) and 'higherweight' (>50th centile but not meeting criteria for overweight) groups.

To give an index of the degree of compensation that could be averaged across both preload tests, we calculated COMPX scores, using the following equation: COMPX $=($ (lunch calories after low energy preload - lunch calories after high energy preload) / (high energy preload calories - low energy preload calories) $\times 100$ (7). This generates a percentage, where $100 \%$ represents perfect compensation (i.e. eating precisely more in the low energy preload condition to compensate for the calorie difference between preloads), over $100 \%$ represents over-compensation for preload calories (i.e. eating too much after the low energy 
preload and/or too little after the high energy preload), 1-99\% represents some degree of compensation (i.e. eating more after the low energy preload and/or less after the high energy preload, but not enough to compensate fully for the difference in preload calories), $0 \%$ is no compensation, and under $0 \%$ is scored in cases where the calorie content of the preload had the opposite effect, i.e. subjects ate more after the high energy preload and/or less after the low energy preload. The primary measure of average compensation across the two sets of preloads was calculated by taking the mean of the two COMPX scores where both were available. However to obtain more values, we also created a variable using data for children who had COMPX available for either Test A (Test A COMPX), or Test B (Test B COMPX), or either/both (mean COMPX for Test A and Test B where both available, or either Test A or Test B COMPX where only one available).

Pearson's correlations were used to test relationships between Test A, Test B and average COMPX scores, and BMI $\mathrm{z}$ score. To explore the character of compensation further, we created two additional intake variables: junk foods (sum of kcal from mini cheese crackers and mini chocolate cookies), and core food (sum of kcal from chicken, cheese, white bread, green grapes, and cherry tomatoes/carrot sticks). We then conducted repeated measures ANOVAs using either total intake of junk foods (kcal), or total intake of core food (kcal), following low and high energy preloads, as the within-subjects factors, and weight status (normal-weight vs. overweight/obese) as the between-subjects factor.

\section{Results}

\section{Response rates}

Of the 148 eligible children, only 3 were denied parental permission to participate in the study, and 124 (84\%) participated on at least one day of the study. Ninety-three of these participated on the control day, 101 in both trials for Test A, and 102 in both trials for Test B. Ninety-eight children ( $66 \%$ of eligible participants) participated in at least one test, and had anthropometric data available; this group $(\mathrm{n}=98)$ was considered the sample for analysis.

\section{Sample characteristics}

Child and parent characteristics were evaluated for the complete sample ( $\mathrm{n}=98)$. Mean child age was $5.0 \pm 0.4 \mathrm{y}$. There were equal numbers of boys and girls, and $23 \%$ were overweight/ obese according to classifications (obese $n=4$, overweight $n=18,>50^{\text {th }}$ centile $n=44,50^{\text {th }}$ centile $\mathrm{n}=32$ ). The vast majority ( $97 \%$ ) of those completing questionnaires were mothers of the child. Eighty-two percent of participants were white, and 15\% black. Approaching half of those who provided data on education had a degree or post-graduate qualification and, of the $70 \%$ of the sample who reported income data, $13 \%$ had an annual household income less than 20,000 GBP, 33\% between 20,000 and $39,999,30 \%$ between 40,000 and 59,999 , and $23 \% 60,000$ or more.

\section{Caloric compensation and child weight}

Test A (low vs. high energy orange-Of the 101 children present for both Test A preload trials, 95 drank the full $200 \mathrm{ml}$ of preload in each condition, amounting to a preload energy difference of $169 \mathrm{kcal}$, and 90 had complete anthropometric data available (92\% of 
the complete sample of $n=98$ ); analyses of Test A only were based on this sub-sample $(\mathrm{n}=90)$. Mean COMPX score for Test A was $70 \pm 77 \%$ SD (Fig 1). As in other studies, the range of scores (-87\% to $234 \%$ ) was substantial, indicating wide variation in compensation ability between individuals. Using the Test A sub-sample $(\mathrm{n}=90)$ for whom all intake and anthropometric data were available, there was no significant association between COMPX and BMI z score $(\mathrm{r}=-0.07 ; \mathrm{p}=0.510)$. Repeated measures ANOVA revealed significant differences between low and high energy preload conditions for total $(F[90,1]=69.69, \mathrm{p}<$. 001), junk ( $F[90,1]=36.15, p<.001)$, and core food caloric intake $(F[90,1]=26.09, p<.001)$, with greater caloric intake in the low energy preload condition for all food categories (Fig 1). In analyses including weight status, although no preload by weight status interaction was apparent for core food intake, there was a significant interaction between preload and weight status for junk food intake $(F[90,1]=4.17, \mathrm{p}=0.044)$, such that overweight/obese children ate relatively more junk food than normal-weight children after the high energy preload (Fig 3).

Test B (water vs. milkshake-Of the 102 children present for both Test B preload trials, 78 children drank all of each preload, and complete anthropometric data were available for 65 participants (66\% of the complete sample of $n=98$ ). Mean COMPX score for Test B was $51 \pm 58 \%$ SD, with a range of -131 to $200 \%$ (Fig 1). Using the Test B sub-sample ( $n=65)$ for whom all intake and anthropometric data were available, a negative correlation between COMPX and BMI $\mathrm{z}$ score failed to reach significance $(\mathrm{r}=-0.18 ; \mathrm{p}=0.148)$. Repeated measures ANOVAs revealed significant differences between low and high energy preload conditions for total $(\mathrm{F}[65,1]=55.01, \mathrm{p}<.001)$, junk $(\mathrm{F}[65,1]=10.23, \mathrm{p}=.002)$, and core food caloric intake $(F[65,1]=44.89, \mathrm{p}<.001)$, with greater caloric intake in the low energy preload condition for all food categories (Fig 1). In analyses including weight status, no preload by weight group interactions were apparent for core food intake, junk food intake or total food intake.

\section{Mean compensation across preload tests}

Fifty-seven children participated in both Test A and Test B preload tests and had anthropometric data available ( $58 \%$ of the complete sample of $n=98)$. A paired test revealed no significant differences between COMPX scores for Test A and Test B (Test A mean 69.20 $\pm 74.18 \mathrm{SD}$; Test B mean 53.86 $\pm 56.28 \mathrm{SD}$, $\mathrm{p}=0.164)$. Since there was a clear trend toward a positive correlation between COMPX scores for Test A and Test B ( $r=0.23$, $\mathrm{p}=0.082$ ), we proceeded to create a mean value. Mean COMPX score averaged across Test $A$ and Test $B(n=57)$ was $61 \pm 51 \% \mathrm{SD}$, with a range of -57 to $181 \%$. There was a significant correlation between mean compensation and BMI z score (r=-.26; p=.049) (Fig 2a) such that overweight/obese children showed least compensation (41\%), children over $50^{\text {th }}$ centile the next least (59\%), and children under the $50^{\text {th }}$ centile $(80 \%)$ the most (Fig $2 b)$.

To establish whether the negative association with BMI $\mathrm{z}$ in this reduced sub-sample was driven primarily by compensation within one or other of the preload tests, we also re-ran correlations for Test A and Test B separately, using only the 57 children who had data for both tests. For Test A, a negative correlation between COMPX and BMI z score failed to reach significance $(r=-0.23 ; p=0.084)$; the same was true for Test $B(r=-0.17 ; p=0.196)$. 
Additionally, to obtain more COMPX values, we tested associations with BMI z using the sub-sample of children who had data for either Test A or Test B or both ( $\mathrm{n}=98)$. For this analysis, the negative correlation between COMPX and BMI z score failed to reach significance $(r=-0.07 ; \mathrm{p}=0.471)$.

One sample $t$ tests demonstrated that each of the analysis sub-samples used above did not differ from the full sample on child BMI and age, maternal education, or compensation scores.

\section{Discussion}

In this study, which used two different preloading paradigms (low vs. high energy orange, water vs. milkshake) we observed a negative relationship between intake regulation and adiposity such that, on average, overweight/obese children showed least compensation for the difference in preload calories $(41 \%)$, children over $50^{\text {th }}$ centile the next least $(59 \%)$, and children under the $50^{\text {th }}$ centile (80\%) the most. These results suggest not only that overweight/obese children compensate less well than normal-weight children, but, among the currently normal-weight, heavier children compensate less well under the particular conditions we tested here - a behavior that may place them at greater risk for becoming overweight in the future (26). For the condition using preloads with minimal organoleptic differences (low vs. high energy orange) only, overweight/obese children showed relatively poorer preload compensation than normal-weight children in terms of the junk foods eaten at lunch, but not in terms of the core foods eaten. These results suggest that, under certain conditions, overweight/obese children's preferences for obesogenic/junk foods may overwhelm intake regulation mechanisms within multi-item meals.

Our findings regarding overall compensation levels are broadly consistent with several other preloading studies demonstrating poorer compensation in higher weight children $(7,27)$ and adults $(8,28)$. Our findings are less consistent with those of Faith (11) who reported higher average COMPX scores than us (104\% vs. 61\%) in a sample of 3-7 y olds, but found no relationship with BMI z score. The authors suggest that the lack of association in this study may have been attributable to the small sample size and a lack of power due to the fact they were studying sibling pairs ( $n=32$ sibling pairs vs. $n \geq 57$ in the current study). Cecil et al (12) also reported a lower mean COMPX score of $51 \%$ using preloads with disguised cues, as well as no relationship with BMI. However, their subjects were slightly older than ours (6-9 y vs. 4-5 y) and there is some evidence that younger children may compensate better than older children $(29,30)$, so this could explain the divergence from our results. Moreover, direct comparison of COMPX scores across studies is only meaningful where the energy difference between preloads is equivalent. It was notable that we observed a weight by preload interaction for junk but not core food intake only in the condition using preloads with disguised caloric cues. It is unclear why this should be, although some generalization from sensory properties of the sweet and fatty milk shake to the 'junk' food may have limited appetite for those foods after preload B. However this condition gave more variable compensation rates than the undisguised condition (SD 77\% vs. 58\%), which could have made the weight effect more visible. 
Formal statistical comparisons of compensation between each of our preloading paradigms are limited by sample size limitations and potential order effects. However it was notable that compensation scores appeared to be lower for the water vs. milkshake condition (Test B). This is contrary to predictions based on expected satiety, given that when the caloric difference is created by adding an undetectable form of carbohydrate to the high-calorie preload (as in Test A and $(7,20,28)$ ) the child is forced to rely on internal satiety sensations alone, which may be minimally different when offered lunch 30 mins later, whereas when the familiar foods or beverages are used for each condition (12) external cues are additionally available. A number of explanations are possible. For example, perhaps since most children are accustomed to drinking high calorie drinks such as milkshake prior to or during the consumption of meals, this habit overcomes their short-term satiety responses to such drinks, or prevents them from associating the sensory properties of the drinks to later post-ingestive effects. This would be consistent with studies reporting higher intakes among children when they are offered milk rather than water at a standard lunch (31), and when they are offered a palatable chocolate milk rather than plain milk, which both suggest that milk-based - and particularly palatable milk-based - drinks might increase children's caloric intake. It is also possible that heavier children may have had more experience with similar energy-rich milkshake drinks than less heavy children, allowing a slight learned advantage in compensation ability, despite any tendency for poorer discrimination from internal cues. In contrast, the disguised drinks used in Test A may tap more directly children's sensitivity to these physiological sensations, leading to unconscious adjustment of intake. Our observations could also arise from the milkshake having a greater appetizing or disinhibiting effect on intake more than did the 'disguised' high-calorie orange drink. This would be consistent with results from Yeomans et al (23) who found that increased palatability of a test meal was associated with decreased compensation in participants. There may also have been confounding from an order effect created by the fact that Test B always followed Test A. For example, children may have felt more comfortable with the lunch contents and setting for Test $\mathrm{B}$, maximizing the chance for individual differences in compensation ability to be expressed.

Differences between Test A and Test B compensation may also have been driven by macronutrients within the preloads used. For example, some studies suggest that fat is inherently less satiating than protein or carbohydrate, and that people are therefore less likely to adjust subsequent intake to compensate for the energy content in a high fat meal $(32,33)$ such as the milkshake preload used here. Further, Fricker (9) found that while lean individuals reduced fat intake in ad libitum meal following a low fat preload meal, obese individuals increased fat: energy ratio, suggesting relatively poorer compensation for fat in heavier individuals. However others argue that compensation is not macronutrient-specific (34), and that any relative difficulty people have in compensating for fat is more likely to result from its increased energy density relative to protein and carbohydrate than from unique properties of fat. Indeed, other studies have demonstrated greater appetite suppression with high fat preloads when they are ingested rather than intragastrically administered (35). It is therefore unlikely that differences in the physiological effects of the preloads wholly explained the present findings. 
It was also notable that fewer children drank all of the Test B preloads (78/102 for Test B vs. 95/101 for Test A). This was likely due to the milkshake being more satiating than the Test A high calorie preload and could potentially create a bias in the sample if those who completed Test B were lower in satiety responsiveness and poorer at compensation. Arguing against this possibility, there was no evidence that Test B completers were different from the rest of the sample in terms of Test A compensation scores, or BMI. However, the fact that the relationship with weight emerged even after potentially excluding some children with relatively good compensation ability speaks to the strength of the observed relationship.

Features of our study design conferred advantages but also some limitations. For example, the study was conducted in participants' schools with children eating together at tables as for their normal lunch session. This afforded us experimental control while allowing more ecological validity than is available in a laboratory setting in which children typically eat alone. However, eating with peers may have impacted eating behaviors due social norms and other social processes and results may not therefore be generalizable to other free-living eating situations e.g. eating at home. Our averaging approach increases confidence in our findings by demonstrating weight effects over two different challenges. Notably, compensation in many studies is highly variable (e.g. range of -80 to $230 \%$ in Johnson \& Birch (7), range of -121 to $218 \%$ in Birch et al (28), SD of 107\% in Faith et al (11), probably due in part to random experimental factors producing noise in the data. We were able to overcome this by calculating a compensation estimate based on two paradigms and it is notable that the SD for our averaged measure was $51 \%$ and the range -57 to $181 \%$, compared to an SD of $77 \%$ and a range of -87 to $234 \%$ for Test A, and $58 \%$ and -131 to $200 \%$ for Test B. A limitation of our averaging approach, however, was that the sample size was much reduced for the combined analysis, limiting power. One might also argue that each preloading paradigm tapped very different regulation processes and compensation values and involved different energy differences, and should not therefore be combined; however the positive correlation we observed between compensation in each test supports some intra-individual consistency between paradigms.

To conclude, our results suggest that caloric compensation is indeed poorer in heavier children. Furthermore, our study provided a stimulating suggestion that failure to compensate among overweight/obese children may be more likely when high-calorie junk foods rather than healthier, core foods are given. Future studies should explore this more formally by more systematically varying food categories in both preloads and test meals, using counter-balancing. For example it would be informative to test whether heavier vs. leaner children show poorer preload compensation at an all junk-food meal as compared with an all core-food meal, and whether the macronutrient compensation of the preload affects the compensation by weight interaction. However, if it is indeed true that overweight/ obese children's preferences for obesogenic/junk foods overwhelm intake regulation mechanisms within multi-item meals, then limiting available foods to relatively healthy core food items may prevent this from happening. 


\section{Acknowledgments}

Dr. Carnell is supported by the National Institute of Diabetes and Ingestive and Kidney Diseases (NIDDK) (Grant Number R00DK088360), and the Eunice Kennedy Shriver National Institute of Child Health and Human Development (NICHD) and Office of the Director, National Institutes of Health (OD) under Grant Number U54HD070725 to the Global Obesity Prevention Center (GOPC) at Johns Hopkins. We thank the Coordenação de Aperfeiçoamento de Pessoal de Nível Superior (CAPES) for scholarships for LAM and SW. The work conducted was funded by a Medical Research Council (MRC) PhD studentship to Dr. Carnell. The authors are extremely grateful to Jane Wardle for her essential contributions to the study design, and early thoughts on presentation of the results. Many thanks also to Lucy Cooke and others at the Health Behavior Research Centre for invaluable help with data collection, and to Elissa Driggin for contributions to structuring of an early draft.

\section{References}

1. Fomon, SJ. Nutrition of normal infants. St. Louis: Mosby-Year Book, Inc.; 1993.

2. Davis CM. Results of the Self-Selection of Diets by Young Children. Can Med Assoc J. 1939; 41(3):257-61. [PubMed: 20321464]

3. davis C. Self selection of diet by newly weaned infants. Am J Dis Child. 1928; 36:651-79.

4. Birch LL, Deysher M. Caloric compensation and sensory specific satiety: evidence for self regulation of food intake by young children. Appetite. 1986; 7(4):323-31. [PubMed: 3789709]

5. Birch LL, Johnson SL, Andresen G, Peters JC, Schulte MC. The variability of young children's energy intake. The New England journal of medicine. 1991; 324(4):232-5. [PubMed: 1985244]

6. Shea S, Stein AD, Basch CE, Contento IR, Zybert P. Variability and self-regulation of energy intake in young children in their everyday environment. Pediatrics. 1992; 90(4):542-6. [PubMed: 1408507]

7. Johnson SL, Birch LL. Parents' and children's adiposity and eating style. Pediatrics. 1994; 94(5): 653-61. [PubMed: 7936891]

8. Bellissimo N, Desantadina MV, Pencharz PB, Berall GB, Thomas SG, Anderson GH. A comparison of short-term appetite and energy intakes in normal weight and obese boys following glucose and whey-protein drinks. International journal of obesity. 2008; 32(2):362-71. [PubMed: 17700578]

9. Fricker J, Chapelot D, Pasquet P, Rozen R, Apfelbaum M. Effect of a covert fat dilution on the spontaneous food intake by lean and obese subjects. Appetite. 1995; 24(2):121-37. [PubMed: 7611747]

10. Speechly DP, Buffenstein R. Appetite dysfunction in obese males: evidence for role of hyperinsulinaemia in passive overconsumption with a high fat diet. Eur J Clin Nutr. 2000; 54(3): 225-33. [PubMed: 10713745]

11. Faith MS, Keller KL, Johnson SL, Pietrobelli A, Matz PE, Must S, et al. Familial aggregation of energy intake in children. The American journal of clinical nutrition. 2004; 79(5):844-50. [PubMed: 15113724]

12. Cecil JE, Palmer CN, Wrieden W, Murrie I, Bolton-Smith C, Watt P, et al. Energy intakes of children after preloads: adjustment, not compensation. The American journal of clinical nutrition. 2005; 82(2):302-8. [PubMed: 16087972]

13. Remy E, Issanchou S, Chabanet C, Boggio V, Nicklaus S. Impact of adiposity, age, sex and maternal feeding practices on eating in the absence of hunger and caloric compensation in preschool children. International journal of obesity. 2015; 39(6):925-30. [PubMed: 25777357]

14. Brennan IM, Luscombe-Marsh ND, Seimon RV, Otto B, Horowitz M, Wishart JM, et al. Effects of fat, protein, and carbohydrate and protein load on appetite, plasma cholecystokinin, peptide YY, and ghrelin, and energy intake in lean and obese men. Am J Physiol Gastrointest Liver Physiol. 2012; 303(1):G129-40. [PubMed: 22556143]

15. Wilson JF. Preschool children maintain intake of other foods at a meal including sugared chocolate milk. Appetite. 1991; 16(1):61-7. [PubMed: 2018405]

16. Westerterp-Plantenga MS. The significance of protein in food intake and body weight regulation. Curr Opin Clin Nutr Metab Care. 2003; 6(6):635-8. [PubMed: 14557793]

17. Rolls BJ. The relationship between dietary energy density and energy intake. Physiology \& behavior. 2009; 97(5):609-15. [PubMed: 19303887] 
18. Yeomans MR, Blundell JE, Leshem M. Palatability: response to nutritional need or need-free stimulation of appetite? The British journal of nutrition. 2004; 92(Suppl 1):S3-14. [PubMed: 15384315]

19. Forde CG, Almiron-Roig E, Brunstrom JM. Expected Satiety: Application to Weight Management and Understanding Energy Selection in Humans. Curr Obes Rep. 2015; 4(1):131-40. [PubMed: 26627096]

20. Kral TV, Allison DB, Birch LL, Stallings VA, Moore RH, Faith MS. Caloric compensation and eating in the absence of hunger in 5- to 12-y-old weight-discordant siblings. The American journal of clinical nutrition. 2012; 96(3):574-83. [PubMed: 22854400]

21. Adrian TE, Ferri GL, Bacarese-Hamilton AJ, Fuessl HS, Polak JM, Bloom SR. Human distribution and release of a putative new gut hormone, peptide YY. Gastroenterology. 1985; 89(5):1070-7. [PubMed: 3840109]

22. Gibson EL, Wardle J. Effect of contingent hunger state on development of appetite for a novel fruit snack. Appetite. 2001; 37(2):91-101. [PubMed: 11606035]

23. Yeomans MR, Lee MD, Gray RW, French SJ. Effects of test-meal palatability on compensatory eating following disguised fat and carbohydrate preloads. Int J Obes Relat Metab Disord. 2001; 25(8):1215-24. [PubMed: 11477507]

24. Cole TJ, Freeman JV, Preece MA. Body mass index reference curves for the UK, 1990. Arch Dis Child. 1995; 73(1):25-9. [PubMed: 7639544]

25. Cole TJ, Bellizzi MC, Flegal K, Dietz WH. Establishing a standard definition for child overweight and obesity worldwide: international survey. BMJ. 2000; 320:1240-3. [PubMed: 10797032]

26. Carnell S, Wardle J. Appetite and adiposity in children: evidence for a behavioral susceptibility theory of obesity. The American journal of clinical nutrition. 2008; 88(1):22-9. [PubMed: 18614720]

27. Ebbeling CB, Sinclair KB, Pereira MA, Garcia-Lago E, Feldman HA, Ludwig DS. Compensation for energy intake from fast food among overweight and lean adolescents. Jama. 2004; 291(23): 2828-33. [PubMed: 15199032]

28. Birch LL, Fisher JO. Mothers' child-feeding practices influence daughters' eating and weight. The American journal of clinical nutrition. 2000; 71(5):1054-61. [PubMed: 10799366]

29. Johnson SL, Taylor-Holloway LA. Non-Hispanic white and Hispanic elementary school children's self-regulation of energy intake. The American journal of clinical nutrition. 2006; 83(6):1276-82. [PubMed: 16762937]

30. Birch LL, Fisher JO. Food intake regulation in children. Fat and sugar substitutes and intake. Annals of the New York Academy of Sciences. 1997; 819:194-220. [PubMed: 9186769]

31. Hagg A, Jacobson T, Nordlund G, Rossner S. Effects of milk or water on lunch intake in preschool children. Appetite. 1998; 31(1):83-92. [PubMed: 9716437]

32. Blundell JE, Burley VJ, Cotton JR, Lawton CL. Dietary fat and the control of energy intake: evaluating the effects of fat on meal size and postmeal satiety. The American journal of clinical nutrition. 1993; 57(5 Suppl):772S-7S. discussion 7S-8S. [PubMed: 8475895]

33. Rolls BJ, Kim-Harris S, Fischman MW, Foltin RW, Moran TH, Stoner SA. Satiety after preloads with different amounts of fat and carbohydrate: implications for obesity. The American journal of clinical nutrition. 1994; 60(4):476-87. [PubMed: 7661908]

34. Cecil JE, Castiglione K, French S, Francis J, Read NW. Effects of intragastric infusions of fat and carbohydrate on appetite ratings and food intake from a test meal. Appetite. 1998; 30(1):65-77. [PubMed: 9500801]

35. Cecil JE, Francis J, Read NW. Comparison of the effects of a high-fat and high-carbohydrate soup delivered orally and intragastrically on gastric emptying, appetite, and eating behaviour. Physiology \& behavior. 1999; 67(2):299-306. [PubMed: 10477062] 


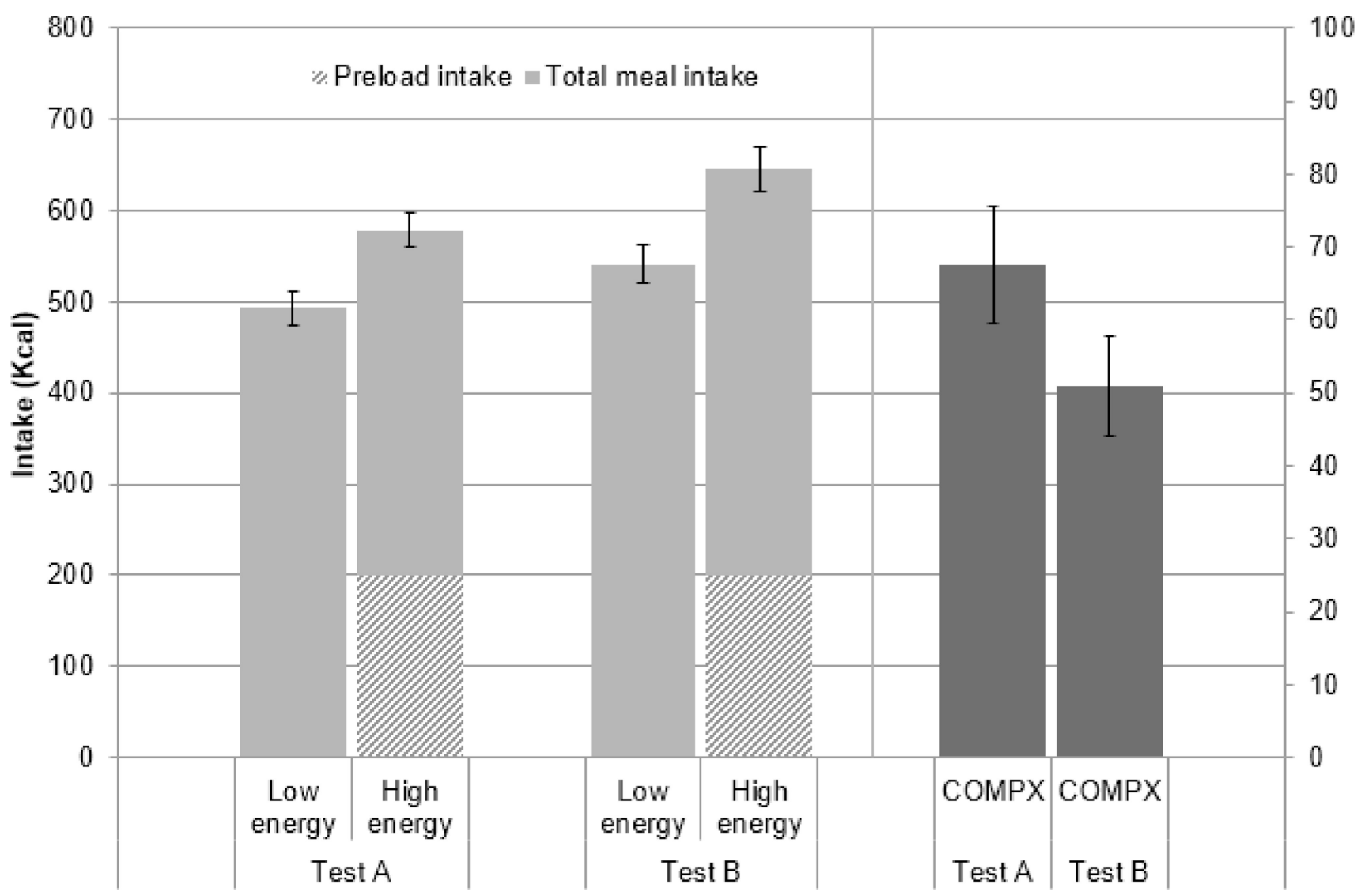

Fig 1.

Preload and total meal intake and caloric compensation scores for Test A ( $\mathrm{n}=90)$ and Test B $(\mathrm{n}=65)$.

COMPX=caloric compensation score. Bars show means with standard errors. 
a:

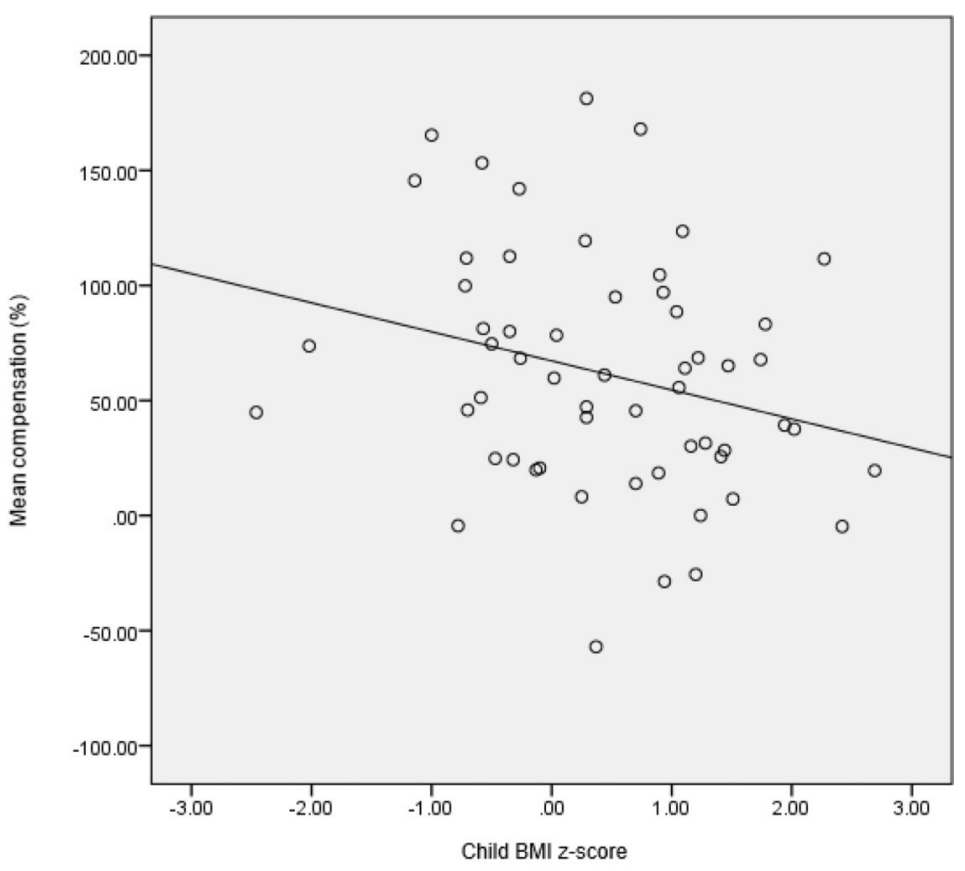

b:

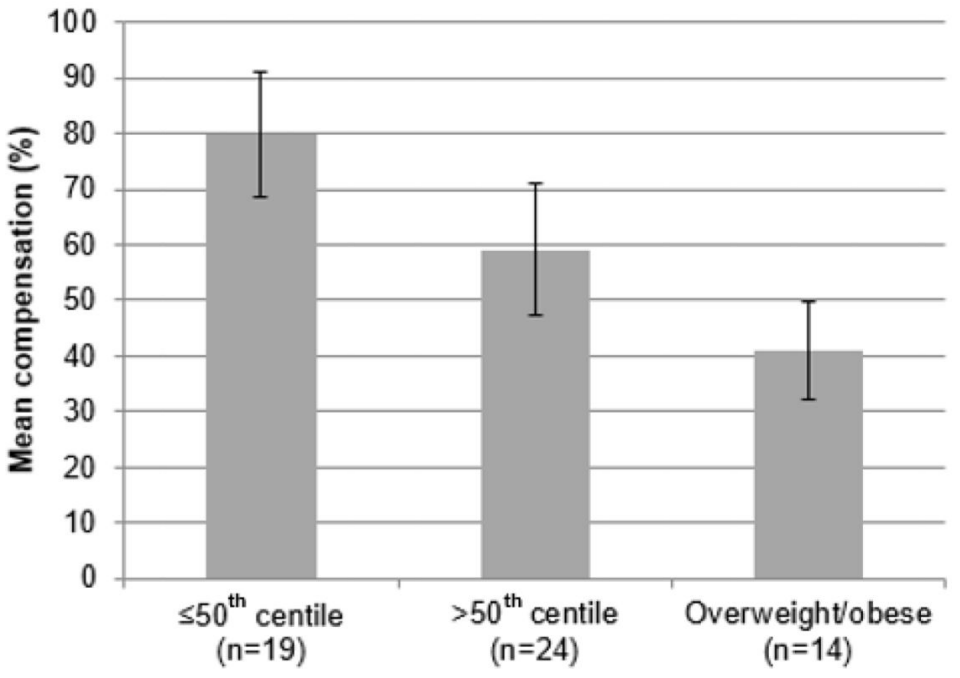

Fig 2.

a: Scatterplot with regression line showing relationship between mean caloric compensation score and BMI z score $(n=57)$.

b: Mean (standard error, SE) caloric compensation score by weight group $(n=57)$. Univariate ANOVA revealed a significant linear trend across weight groups $(\mathrm{p}=0.031)$ and a trend towards a difference between weight groups (lower weight vs. higher weight vs. overweight/ obese) $(\mathrm{F}[56,2]=2.45 \mathrm{p}=0.096)$. 


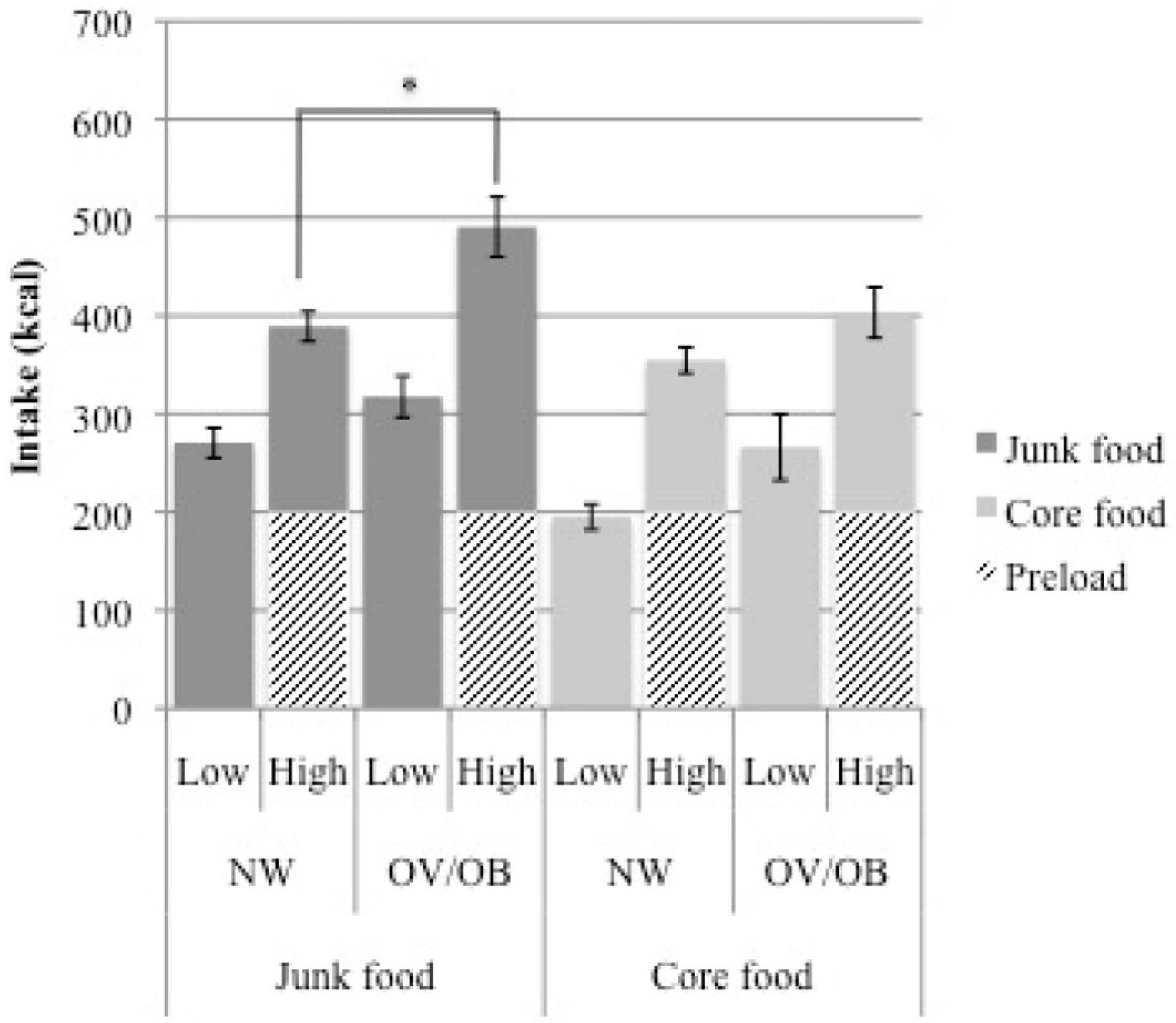

Fig 3.

Preload and junk food intake, and preload and core food intake for 519 Test A ( $n=90)$ in obese/overweight and normal-weight children.

NW: normal weight; OV/OB: overweight/obese; *p<.05, significant interaction between preload condition and weight group. 